\title{
Editorial
}

\section{Questões de Família e Desenvolvimento e a Prática de Pesquisa}

A "família", como um contexto dinâmico e único para crianças em desenvolvimento, tem sido negligenciado como um tópico proeminente, tanto na pesquisa sociológica quanto na psicologia do desenvolvimento. No entanto, recentemente, as questões sobre "família" estão sendo apontadas como uma das tendências futuras na pesquisa em psicologia. Por exemplo, a Revista American Psychologist (Vol. 56, no. 1) dedicou, em janeiro de 2001, a sua seção de "Perspectivas Internacionais" às questões de "família". Esta seção apresenta uma visão global de várias questões e tendências que as famílias e os psicólogos da família enfrentam no início do século XXI (Kaslow, 2001, p. 37).

A necessidade de pesquisas na área de "família", principalmente sob a perspectiva do desenvolvimento humano, que se caracteriza por estudar as fases de desenvolvimento do indivíduo considerando o que acontece na "família" enquanto grupo, tem sido salientada, particularmente, por Kreppner (1992). Para esse autor, a ênfase no contexto familiar e seu impacto sobre o desenvolvimento individual da criança, particularmente durante períodos de transição, ajuda-nos a compreender como os diferentes modos de realizar as tarefas de desenvolvimento podem afetar o desenvolvimento individual (p. 173).

A importância de se compreender o indivíduo no contexto da "família" vem sendo reconhecida há muitos anos (Burguess, 1926), embora a implementação de pesquisas empíricas tenha ocorrido basicamente após a publicação dos trabalhos de Urie Bronfenbrenner, na década de 70. Focalizar a singularidade e a complexidade da rede relacional da "família" permite vislumbrar um novo quadro de "família" como um grupo específico em desenvolvimento, inserido em um contexto cultural também em desenvolvimento. A noção de que a "família" e a cultura constituem contextos essenciais para a compreensão do indivíduo em sua singularidade é claramente destacada nos artigos publicados nessa Seção Especial intitulada "Questões de Família e Desenvolvimento".

Com este número, encerra-se a referida Seção, que foi planejada tendo em vista as considerações acima. Da série programada, restou-nos um artigo que, por razões de ordem técnica, não pode ser incluído neste número e será publicado no Volume 17(1). Trata-se do artigo de Reeta Sonawat, da S.N.D.T. University, Bombay, India, que apresenta uma discussão interessante sobre as "famílias" na sociedade indiana contemporânea. Assim, gostaríamos de agradecer a todos os autores, nacionais e estrangeiros, que contribuíram para a realização desta Seção Especial.

\section{Imagens, representações e família}

Isto posto, no encerramento da publicação da referida Seção, gostaríamos de trazer, para reflexão, alguns pontos relativos ao tema ao invés de apresentar um resumo, ou mes- mo discutir detalhes, de cada artigo apresentado. Preliminarmente, deve ser salientado que, em se tratando de questões e tendências na "psicologia da família", temos de distinguir dois tipos de atuação dos psicólogos: a dos profissionais, exemplificada nos psicólogos clínicos e nos da psicologia escolar, e a dos pesquisadores acadêmicos, focalizando, em particular, a perspectiva do desenvolvimento para os estudos dessa especialidade.

Dessa forma, para os do primeiro grupo, muitas questões se colocam no que toca, por exemplo, ao desenvolvimento da "família edipiana" descrita pela psicanálise, ao estudo de famílias de psicóticos, e as pesquisas sobre os processos de comunicação humana. Nesse sentido, os anos 60/ 70 foram particularmente importantes, pois tivemos os trabalhos de Ronald Laing, David Cooper e outros pesquisadores da Antipsiquiatria, no que tange ao primeiro assunto, e as pesquisas de Gregory Bateson, dentre outros, sobre as relações de duplo vínculo e sua importância nas interações entre genitores e seus filhos. Muitos desafios se colocam também para os terapeutas da "família" e a própria prática da terapia familiar. Considerando a diversidade de formas de viver em "família", na atualidade, que inclui também o modo de vida familiar tradicional, pode-se indagar: com que "família" trabalham os terapeutas da família? Muitas outras questões sobre a "família" e suas transformações estão a pedir reflexão dos profissionais da psicologia.

Já, para os pesquisadores acadêmicos, as questões principais dizem respeito a métodos e instrumentos de pesquisa, bem como aos seus resultados. Para compreender como as "famílias" funcionam, hoje, precisamos, sobretudo, refletir sobre qual é a sua função, que funções tem lhe sido atribuídas e, principalmente, sobre aquelas, de fato, por ela exercidas. (Será que ela funciona ainda como um "lar" ou é somente um "ponto de encontro"?) Tal compreensão necessita ser feita não apenas considerando a perspectiva de cada um dos membros de uma "família", mas também de uma perspectiva sócio-cultural, e que observe as transformações das funções da "família" ao longo da história. Nesse quadro, algumas questões parecem ser fundamentais, tanto para os profissionais quanto para os pesquisadores acadêmicos. Tratase das perguntas que podem ser feitas sobre o modo de formação de uma "família", das imagens que lhe servem de base. Por exemplo, as imagens do "amor romântico" ou as de uma família de telenovela, e as imagens que lhes fornecem ideais, como exemplificado nas imagens da Sagrada Família, da família burguesa, da proletária, da classe média, ou outras.

Cada uma dessas imagens figura valores, define funções, e, naturalmente, papéis sociais. As imagens informam a "realidade" das "famílias", dão-lhe direções, moldam-na. Não somente as imagens, mas outros aspectos fazem com que cada "família" acabe por construir para si uma "realidade" que lhe é própria, a ponto de podermos pensar que é mais 
promissor para a pesquisa falarmos em "realidades das famílias" que procurarmos a "realidade da família". Dessa forma, deve ser salientado que, para o pesquisador, tais realidades devem ser compreendidas em suas singularidades e não tendo em vista uma "realidade da família". Ao nos reportarmos a "realidades das famílias" e, considerando a diversidade de tipos de "famílias" nas sociedades contemporâneas, podemos dizer que interessa menos a família e mais a pesquisa feita junto às famílias existentes.

As "famílias" enfrentam e lidam com problemas trazidos pelo meio ambiente e a cultura de nossa época: a influência da escola, dos meios de comunicação de massa, dos apelos da sociedade de consumo (ex.: as muitas variantes de drogas oferecidas para consumo). Há, também, os problemas surgidos em conseqüência da variedade de concepções de sexualidade correntes e da difusão de padrões de comportamento sexual mais "liberais" (ex.: casamentos homossexuais). Adicione-se a isso, as dificuldades surgidas com as novas imagens da criança. Por um lado, a visão psicanalítica, que trata a criança como um adulto em miniatura e, por outro, a criança autônoma e independente que deve ser compreendida em sua singularidade, conforme mandam os princípios da pedagogia moderna.

As tendências e questões da psicologia da "família" são complexas e não é nossa pretensão tratar delas neste Editorial. Pretendemos, sim, despertar o leitor para a importância de considerar as questões de "família", quer na sua prática profissional quer na sua prática de pesquisa, se se objetiva, de fato, compreender o indivíduo em sua singularidade. Nesse contexto, gostaríamos de apresentar algumas questões relativas a método de investigação científica no estudo de "famílias", na perspectiva do desenvolvimento humano.

\section{Questões teóricas e metodológicas}

Comecemos por lembrar que, assim como temos imagens ou representações de "família" e de formas de vida em "família", também os cientistas têm diferentes modos de representar a "realidade". Trata-se, neste caso, de outro filtro importante na construção da "realidade" de uma "família". Não podemos representar diretamente uma tal "realidade", pois sua representação é mediada pelos instrumentos selecionados para esse fim. Ou seja, os instrumentos de coleta de dados desempenham um papel crucial nesse processo de representação da "realidade investigada". Em outras palavras, os tipos de técnicas e instrumentos que temos usado em pesquisa têm determinado o que sabemos sobre "família e desenvolvimento".

Pensar sobre os modos científicos de representar a realidade significa refletir sobre: (a) em que medida nós estamos sendo bem sucedidos ao produzir conhecimento sobre o assunto investigado e (b) o quanto os instrumentos empregados por nós são apropriados para medir o que nos propomos. Será que o emprego de entrevistas, questionários, escalas, observação do comportamento nos permite conhecer como as "famílias" funcionam? A resposta a esta questão constitui um desafio e se quisermos, de fato, obter uma com- preensão mais ampla das relações familiares, precisamos, pelo menos, tentar respondê-la. Obviamente, isto requer do pesquisador não só competência, mas honestidade e humildade para avaliar se o mecanismo representacional de coleta de dados, escolhido por ele, tem sido apropriado para produzir conhecimento sobre a realidade a ser representada. Qualquer tentativa de resposta à questão envolve perguntas mais complexas como:

1. É a nossa abordagem teórica útil, no sentido de nos ajudar a responder questões relevantes e nos orientar em direção à compreensão do funcionamento das "famílias" e dos processos de desenvolvimento humano, nos dias de hoje?

2. São os nossos instrumentos mecanismos apropriados para responder questões sobre as "famílias" em desenvolvimento em um contexto também em desenvolvimento? São eles apropriados para representar o mesmo segmento da realidade familiar que estamos tentando capturar? Se sim, quais, como e em que situações?

3. São os nossos instrumentos sensíveis o suficiente para medir as dimensões das relações familiares, tomando como base contextos culturais diferentes?

Além destas questões teóricas e metodológicas, chamamos a atenção para alguns aspectos que permeiam a nossa prática de pesquisa (ver, também, Dessen \& Lewis, 1998) e que, portanto, deveriam fazer parte de nossas reflexões rotineiras enquanto pesquisadores da área de desenvolvimento familiar. O primeiro deles refere-se ao quanto estamos utilizando a diversidade cultural para estudar "famílias" e, ao mesmo tempo, sendo sensíveis à conseqüente complexidade de pesquisas comparativas. É notória a escassez de estudos que têm como objetivo comparar os diferentes grupos sociais em uma mesma cultura, embora tal tendência seja evidente, atualmente. Além disso, os papéis maternos e paternos são multidimensionais, complexos e variados e precisam ser considerados em uma perspectiva cultural, histórica e intergeracional.

Estudar a "família", incluindo todos os seus membros, e refletir sobre a complexidade de nosso planejamento de pesquisa são aspectos a serem, obrigatoriamente, considerados. Quais as implicações metodológicas de se incluir todos os membros da "família" como informantes, em um único projeto de pesquisa? Que diferenças podemos esperar coletando dados de vários subsistemas componentes da "família"? É mais apropriado separar ou agrupar os dados fornecidos por múltiplos informantes? Com certeza, incluir todos os membros da "família" na amostra de um projeto não é tarefa fácil, o que torna tal empreitada desestimulante para muitos pesquisadores, principalmente no Brasil, onde as condições de pesquisa são, de fato, precárias. No entanto, um mínimo de subsistemas precisa ser incluído para que possamos ter um grau maior de certeza sobre o conhecimento produzido a respeito do segmento da realidade que estamos recortando, isto é, no mínimo díades e tríades. Além disso, precisamos conhecer os vários níveis de envolvimento de cada membro da "família" (ou de cada membro da díade ou tríade em foco), porque cada um deles pode fornecer contribui- 
ções específicas para a "família" no curso de seu desenvolvimento. E, para compreender o desenvolvimento do indivíduo em suas diferentes etapas do ciclo de vida, ao longo de diferentes gerações, precisamos compreender o desenvolvimento familiar.

Para capturar as sutilezas das relações entre os diferentes subsistemas familiares, necessitamos desenvolver uma linguagem comum para descrever as relações familiares, criando instrumentos apropriados para a coleta de dados tanto dentro como fora da "família", isto é, instrumentos que sejam capazes de capturar os segmentos da "realidade" em diferentes níveis, conforme proposto por Bronfenbrenner (1999). Esta tarefa requer que reconheçamos, sobretudo, que tanto a coleta quanto a linguagem e a(s) teoria(s) desenvolvidas fazem parte de uma estrutura de suposições e princípios em que tanto nós, pesquisadores, como as "famílias", participantes da pesquisa, trazem para a investigação. A questão principal é: estamos nós, pesquisadores brasileiros, de fato preocupados em desenvolver uma linguagem comum apropriada para descrever os papéis maternos e paternos e a dinâmica das "famílias" brasileiras, de acordo com a diversidade de nossos contextos culturais?

Nós precisamos rever, também, os nossos planejamentos e a maneira como estamos investigando as questões sobre "famílias" no Brasil, persistindo na idéia de que planejamentos longitudinais e abordagens multimetodológicas são mais adequados para capturar a complexidade da dinâmica familiar e dos processos de desenvolvimento. As dificuldades práticas inerentes ao emprego de uma tal abordagem, como alto custo financeiro e possíveis problemas de relacionamento entre os membros da equipe, requerem, do pesquisador, uma certa "dose" de imaginação e criatividade no planejamento e implementação de projetos de pesquisa. Mas, não é simplesmente usando delineamentos longitudinais e dados provenientes de diferentes grupos sociais que responderemos, satisfatoriamente, ao desafio de compreender como as "famílias" funcionam.

Para compreender como as "famílias" funcionam nas sociedades contemporâneas é preciso estudar, em profundidade, as interações e relações entre os diferentes subsistemas familiares, tendo como base a adoção de um conceito de "família" que seja apropriado ao contexto histórico e sócio-cultural do qual elas, "as famílias", fazem parte (ver Petzold, 1996, para maiores detalhes sobre o conceito atual de "família"). Repensar os conceitos de "família" que vigoram atualmente implica refletir sobre a adequação dos conceitos propostos ao método empregado. Por exemplo, devemos adotar uma definição que englobe a pluralidade de formas familiares existentes numa dada cultura, em um determinado tempo histórico, levando em conta as relações entre gerações?

O último aspecto a ser ressaltado diz respeito às questões referentes à ética na pesquisa. Evidentemente, também não nos deteremos na discussão de um tópico tão extenso e complexo, apesar de sua importância. Apenas queremos destacar o fato de que quando os procedimentos de pesquisa não são claramente definidos, os pesquisadores se baseiam em suas próprias opiniões pessoais e visões particulares de mo- ral para determinar o que é e o que não é ético. Portanto, é necessário que os pesquisadores se familiarizem com as Diretrizes e Normas Regulamentadoras de Pesquisa Envolvendo Seres Humanos, do Conselho Nacional de Saúde, de abril de 1997, e também da Resolução CFP No. 016/2000, que dispõe sobre a realização de pesquisas em psicologia com seres humanos.

\section{Considerações finais}

Precisamos reconhecer que há vários tipos de "famílias", que os papéis maternos e paternos são multidimensionais e complexos e que pais e mães desempenham papéis diferentes em contextos culturais diferentes. Para compreender como a "família" funciona, é preciso, sobretudo, estudar as interações e relações desenvolvidas entre os diferentes subsistemas familiares, o contexto histórico, social e econômico no qual as "famílias" estão inseridas e a "família" em diferentes contextos culturais. Estudar a diversidade cultural favorece o desenvolvimento de teorias mais claras e a construção de conceitos mais válidos de "família". A publicação dos 13 artigos que compõem esta Seção Especial nos permite ilustrar as noções discutidas neste Editorial e nos dá a certeza de que os dados coletados e as teorias que desenvolvemos estão diretamente relacionados ao $o$ que o pesquisador e as "famílias" trazem para a investigação.

Gostaríamos de finalizar esse Editorial fazendo um agradecimento especial a Denise Fleith, não só pelo excelente trabalho que vem realizando como Secretária de Divulgação da Revista, como pela ajuda prestada na revisão final dos manuscritos de língua inglesa da Seção Especial que ora encerramos.

\section{Referências}

Bronfenbrenner, U. (1999). Environments in developmental perspective: Theoretical and operational models. Em S.L. Friedman \& T.D. Wachs (Orgs.), Measuring environment across the life span: Emerging methods and concepts. Washington, DC: American Psychological Association.

Burgess, E. W. (1926). The family as a unity of interacting personalities. The Family, 7(1), 3-9.

Dessen, M. A. \& Lewis, C.(1998). Como estudar a família e o pai? Cadernos de Psicologia e Educação Paidéia, 8, 105-121.

Kaslow, F. (2001). Families and family psychology at the millennium. American Psychologist, 56, 37-46.

Kreppner, K. (1992). Developing in a developing context: Rethinking the family's role for children's development. Em L.T. Winegar \& J. Valsiner (Orgs.), Children's development within social context (pp. 161-179). Hillsdale: Lawrence Erlbaum.

Petzold, M. (1996). The psychological definition of the family. Em M. Cusinato (Org.), Research on family resources and needs across the world (pp. 25-44). Milano-Italia: LEDEdizioni Universitarie.

Maria Auxiliadora Dessen Norberto Abreu e Silva Neto 